\title{
The Real Consequences of Property Tax Compression For Oregon Public Schools
}

\author{
Andrea Vedder and Matt Davis, ${ }^{*}$ Department of Economics
}

\begin{abstract}
Since Oregon's stringent property tax reforms in the mid-1990s, tax limitations have created a complex and somewhat unpredictable levy system for local public service administrators who rely on property taxes to fund their operations. School districts, in particular, have hit the tax limitations and been forced to reckon with expected but uncollected ("compressed") property tax revenue. This study examines the relationship between property tax compression rates and school production in Oregon, which we measure with the district-wide percentage of eighth grade students who meet or exceed state standards in the mathematics assessment. From the Oregon Departments of Education and Revenue, we've compiled a panel data set on 147 school districts over the six academic years from 2006-2007 to 2011-2012. We've created an Ordinary Least Squares model designed to control for demographic, financial, and fixed district and year effects that may affect a district or year's overall level of student achievement, and attempt to isolate the effect that property tax compression has on district production. Our results indicate that there is a significant quadratic relationship between property tax compression rates and student achievement, such that while low levels of compression have positive effects on achievement, compression rates above 17.33 percent will negatively affect production. Simply put, our results indicate that a small amount of tax compression paradoxically benefits school districts, but that high tax compression rates bring down a district's percentage of students who pass state mathematics exams.
\end{abstract}

\section{INTRODUCTION}

Property taxes in Oregon are a messy system, and they are poorly understood by most of the state's constituents. In Oregon, property taxes are based on the lesser of two property valuesassessed value, which is capped at a low growth rate, or real market value, which is determined at irregular intervals by county assessors - and a total dollar cap of $\$ 15$ per $\$ 1,000$ of that lesser value (1.5 percent). When a property tax is levied, it is only collected up to that cap; the amount not collected is "compressed" tax revenue, and the uncollected tax as a consequence of the cap is "compression." The major problem with compression is that even when the public votes to fund a project or a local government entity with property taxes, that project or entity may not receive those funds. Some school districts are losing millions of dollars to tax compression-millions of dollars that the community voted to give the district, but that the district can't collect or spend.

Moreover, some properties' "value" is egregiously lower than their sale price. Take, for example, the home at $4239 \mathrm{NE} 7$ th Avenue in Portland, Oregon, which sold on April 1, 2014 for 
\$490,000-it is a beautiful, refurbished, 4-bedroom, 3-bathroom Victorian on a corner lot, just eight blocks from a Whole Foods grocery store. But in 1996, it was dilapidated, smack in the middle of a high-crime neighborhood, and assessed at a value of just $\$ 14,030 .{ }^{1}$ Whoever bought that home will pay just $\$ 339$ in property taxes this year, when 1.5 percent of the $\$ 490,000$ purchase price would be $\$ 7,350$.

Another potential problem with tax compression is that a service the public has voted to fund is not only not actually being funded to the public's specifications, but has also been "paid for" in the voters' minds, and may therefore garner much less political support for future or concurrent supplemental funding, such as from the state general fund. Consider, for example, whether a typical citizen would vote to approve a local option levy in their district for $\$ 10$ million, if just two years earlier a local option levy for \$25 million had passed. Likely, that voter would doubt that the district really needed the additional funds. The reality may be that the district never collected all \$25 million, or even half of it.

If this is the case, and property tax compression presents a situation in which a valued and demanded service is simultaneously underfunded and hindered from successfully securing other public funding sources, then compression could be affecting Oregon's public servicesincluding K-12 education-to a degree far beyond what the simple subtraction of collected tax from levied tax could tell us.

\subsection{A BRIEF EXPLANATION OF OREGON PROPERTY TAX REFROM AND COMPRESSION}

Oregon established its property taxes in the mid-nineteenth century, and almost nothing within this system changed until the 1990s. Prior to the changes, Oregon had a levy-based system, in which local entities would set their own tax rates based on their needs and estimate revenue based on the real market values of area homes. Tax rates varied depending on which taxing district a home lay within. These taxes funded schools at a rate no greater than $\$ 15$ per $\$ 1,000$ of real market value.

In the 1990s, Oregon saw a rash of statewide ballot measures aiming to radically change the property tax system in Oregon. One of the most significant of these was Measure $5^{--a}$ state constitutional amendment passed in 1990 and fully implemented in 1992. This measure placed limits on the amount of tax that could be collected from a property. These limits were $\$ 5$ per $\$ 1,000$ of assessed value for school districts (phased in over three years), and $\$ 10$ per $\$ 1,000$ of assessed value for general local government expenses.

In 1997, Measure 50, another state constitutional amendment, further restricted the property tax system in Oregon by establishing limits on the growth rates of taxable property value, ostensibly to make property tax payments more predictable and to shelter homeowners from wild fluctuations in the real estate market. Taxable property value was defined as the 1996

${ }^{1}$ See Figure 8 in appendix for more information on this property's values and tax rate. 
assessed value of a property, plus a 3 percent annual increase; this value is referred to as a home's assessed value. (New homes' assessed values are their original assessed value, plus a 3 percent annual increase.)

Tax compression is the effect of a passed tax increase, either in the form of a permanent rate increase or a local option levy, hitting the Measure 5 dollar-limit per $\$ 1,000$ of either a property's Measure 50-defined assessed value or its real market value, whichever is lesser. When tax compression occurs, only tax revenue up to each property's limit is collected and distributed amongst the government entities expecting property tax revenue to fund their budgets.

Local option levies-passed most often by public service districts like fire, police, and schools, to fund building renovations or other atypical expenses-are the first in line to lose revenue to tax compression. If a levy's collected taxes for a property are reduced to zero and tax compression is still in effect for that property, then permanent rate tax collection is reduced until the tax cap dollar-limit is reached.

This process is complex and confusing, leaving many Oregonians unaware that funding measures they supported on the ballot could be limited or eliminated by property tax compression. Local government officials and school district administrators themselves may not understand or anticipate the effects of tax compression on their revenue stream, and may not be accounting for it in their budgets.

\subsection{OREGON PROPERTY TAXES AND K-12 EDUCATION}

Property taxes in Oregon are essentially separated into two pools: taxes for local education, and taxes for every other local service. The two pools are taxed at different rates, and face different caps, with education funding being the most straightforward to measure and track. ${ }^{2}$

Before Measure 5 passed in 1990, property taxes paid for approximately 70 percent of Oregon's public education; by the 2011 school year, property tax revenue averaged just 30 percent of an Oregon district's revenue (Linhares, 2011). A cursory glance at the data shows that Oregon's school districts are experiencing property tax compression in greater numbers and at a greater magnitude than local governments and other local public services, which makes Oregon school districts a prime choice for examination of the real effects of property tax compression.

\subsection{THE LINK BETWEEN TAX COMPRESSION AND STUDENT OUTCOMES}

This study attempts to measure the effects of property tax compression on Oregon's education production by regressing the rate of compressed tax (as a percentage of total tax levied) on the percentage of eighth grade students who meet or exceed state standards on the mathematics assessment. The primary aim of this research is to determine whether tax compression has an effect on school outcomes that is distinct from the effects of the existence of a tax cap, or a reduction in overall funding levels. Given that tax compression in a school district

\footnotetext{
${ }^{2}$ Fee Figure 9 in appendix for an example of property tax distribution in Wasco County, Oregon.
} 
is effectively a measured gap between that district's voters' demand for education funding and the district's actual education funding supply, we hypothesize that, at high levels of property tax compression, we may see negative results in education production.

Our principal finding is that property tax compression does have an effect on student achievement, significant at the 5 percent level. Tax compression positively affects student outcomes (at a diminishing rate-of-growth) until a school district reaches a tax compression rate threshold of 8.66 percent, after which point the positive effects of tax compression on student achievement begin to decline as the tax compression rate continues to increase. According to our model, the effects of tax compression remain positive until a total compression rate of 17.33 percent is reached; we predict that compression rates above 17.33 percent will negatively affect student achievement, although no Oregon district has yet reached that threshold (the highest compression rate in Oregon was in Morrow School District in 2012, at 16.83 percent).

\section{LITERATURE REVIEW}

Although several economic studies have looked at the link between school district funding and student performance, and a few have examined the impact that local tax limits have on school districts (both in terms of district funding and district-level student performance), none have attempted to answer the question of whether local tax compression has an effect on student performance.

There is a strong basis for investigating the unique effects of compression. While much of the existing literature examining the link between school funding and student performance finds few to no significant effects (Hanushek, 1986, 1989, and 1997; Hoxby, 2004), research examining property tax inputs specifically has found stronger links between tax revenue limitations and declines in student performance (Downes and Figlio, 1998; McMillen and Singell, 2007). In particular, Downes and Figlio (1998) find that a state's imposition of tax or expenditure limits on local government (including schools) significantly reduces the mean student performance in that state on standardized math tests, and that the reduction in scores is greater for poorer district areas. The authors use detailed data on individual students from the National Longitudinal Survey of the High School Class of 1972 and the National Educational Longitudinal Survey to control for demographics, and Census data to determine school district qualities, including the existence of local tax limitations, and compare student achievement levels on standardized reading and mathematics assessments in 1972 and 1992. They find no significant effect on reading scores, but did find relative reductions in the mean mathematics score to the order of 5.5 to 6 percent in states that implemented a tax limit in the 1970 s or 1980 s.

Both Dye, et. al. (2005) and McMillen and Singell (2007) find a negative relationship between property tax limitations, or "caps," and school district expenditures. McMillen and Singell (2007) find a significant decrease in district-level per-pupil expenditures in states that adopted a tax limit reform between 1990 and 2000, but a less-consistent relationship between class size and the same districts, suggesting that decreases in revenue most greatly affect non- 
instructional costs. This finding is consistent with what one might expect from a unionized school district, in which instructional costs are nearly fixed. Dye, et. al. (2005) examine whether the revenue impacts of capped property taxes for school districts compound over time as a result of "assessed value" growth limits that err on the conservative side, and they find that while tax caps do reduce the growth of total school district expenditures, the effects do not seem to be any less binding in the short-run (two to three years) than in the long-run (nine years).

Although the existence of property tax caps in a district has been linked to lower expenditures and lower average student performance on mathematics assessments, no study that we know has attempted to measure the relationship between the amount of property tax lost to the cap and these same outcomes. Relatively little is known about the relationships between lost-compressed-property tax revenue and school district inputs or production. By measuring the rates of compressed tax revenue relative to the expected total tax revenue of a district, we hope to capture the unique effects of tax compression in the education production function-namely, the disconnect between a community's demand for education (the levied tax) and its true education inputs (the collected tax).

\section{HYPOTHESIS AND METHODOLOGY}

We believe there are unique effects captured by property tax compression, more complicated than the simple fact of an imposed tax limitation. Compression in a school district represents a disconnect between the district's demand-on the part of the voters-for education funding of a certain caliber, and the district's actual education supply; the rate of compression essentially measures the magnitude of that disconnect. It stands to reason that, at high levels of property tax compression, we may see negative results in education production.

Is property tax compression affecting Oregon's public school outcomes? We are testing this question by examining the relationship between a district's tax compression rate and its student achievement levels, which we are measuring with the district's percentage of eighth grade students who meet or exceed Oregon state standards in the annual statewide mathematics assessment. We expect to find that an increase in a district's tax compression rate leads to a decrease in student achievement levels.

Eighth grade mathematics assessment scores are a well-established gauge for education production (Hanushek and Raymond, 2005; Hoxby, 2004), and they may best capture the true effects of a school district's contribution to a student's learning. By age 13, students have surpassed the period during which their performance levels in school are largely dictated by parental involvement and guidance, but are not yet running up against the complications of high school-level measurement, where math classes and ability levels can range from pre-algebra to college-level integral calculus. Comparatively, reading tests are too easily susceptible to a student's interest and ability level developed outside of the classroom. Controlling for demographic and financial effects that may affect a district's overall level of student achievement, we hope to isolate the effect that property tax compression has on district production. 


\subsection{REGRESSION EQUATION}

We have run an Ordinary Least Squares regression to test our hypothesis.

Our final regression equation is as follows:

(1) MathSuccess $=\beta_{0}+\beta_{1}$ TaxCompressionRate $+\beta_{2}$ TaxCompressionRate $^{2}+$

$\beta_{3} \log$ StudentCount $+\beta_{4}$ MinorityPercentage +

$\beta_{5}$ MinorityPercentage ${ }^{2}+\beta_{6}$ Free $/$ RedLunchPct $+\beta_{7}$ Year +

$\beta_{8}$ Year $+\beta$

Our endogenous variable, MathSuccess, is the percentage of eighth grade students who have met or exceeded the Oregon state standards for mathematics in a given school district during a given academic year, measured on a scale of o percent to 100 percent (not as a decimal). Our exogenous variable-of-interest, TaxCompressionRate, is the percentage of the total property tax levied (the permanent tax plus any local option levies) in a given school district during a given academic year that was compressed, calculated as the total number of compressed dollars divided by the total number of levied dollars and measured on a scale of o percent to 100 percent. TaxCompressionRate ${ }^{2}$ is the square of the variable TaxCompressionRate.

Other exogenous variables included in our final regression are: logStudentCount, the log of the total number of students in a given district during a given academic year;

MinorityPercentage, the percentage of the total number of students in a given district during a given academic year who are non-white, measured on a scale of o percent to 100 percent; and MinorityPercentage ${ }^{2}$, the square of the variable MinorityPercentage. To capture fixed effects in each district each year, we've also included the binary exogenous variables Year and District.

We expected to find a negative relationship between TaxCompressionRate and MathSuccess, with the presumption that each percentage-point unit of TaxCompressionRate represents a fairly significant portion of a district's expected budget, and that it is missed when lost. In the case of the Crow-Lorane-Applegate School District in 2012, illustrated in Figures 1 and 2, the lost tax revenue constitutes one-sixth of the district's expected property tax revenue, or-assuming that property taxes in Crow-Lorane-Applegate roughly match the statewide averages for local funding totals (Linhares, 2011)-fully 5 percent of the district's operating budget for the year. It is hard to imagine that this wouldn't negatively impact the district's production, and, all the more so if tax compression is unexpected by school district administrators.

\section{DATA DESCRIPTION}

The data sources for the empirical analysis are the Oregon Department of Education's annual reports on school district budgets, demographics, and assessment results, as well as property tax compression data compiled in 2013 by the League of Oregon Cities from the 
Oregon Department of Revenue's annual reports on property tax levies and collections, which are specific to school district and county.

We've compiled a panel data set that spans the academic years 2006-2007 to 2011-2012 and includes observations from each Oregon school district each year on the following: the total number of students in the district, as well as the percentage of non-white students and the percentage of students on free or reduced lunch programs; the percentage of eighth grade students who've met or exceeded state standards in mathematics; the district's total operating budget, as well as the district's breakdown budgets for capital expenditures, instruction, and support services; and finally the district's rates of permanent rate tax compression, local option levy tax compression, and total (combined permanent rate and local option levy) tax compression, each expressed as a percentage of the tax levied by the district. Figures 1 and 2 illustrate the calculation of the three tax compression rates for the Crow-Lorane-Applegate School District in Lane County in 2012.

We've mapped our annual data as follows: tax compression data for 2007 is based on the results of the 2006 election cycle (which affected the 2006-2007 school year budgets); district budgets, demographics, and assessments results for 2007 are based on the reports published July 1, 2007 (which correspond to the 2006-2007 school year).

\section{FIGURE 1}

\section{Crow-Lorane-Applegate School District Levied Property Tax, 2012}

\section{total tax levied: $\$ 1,389,248.45$}

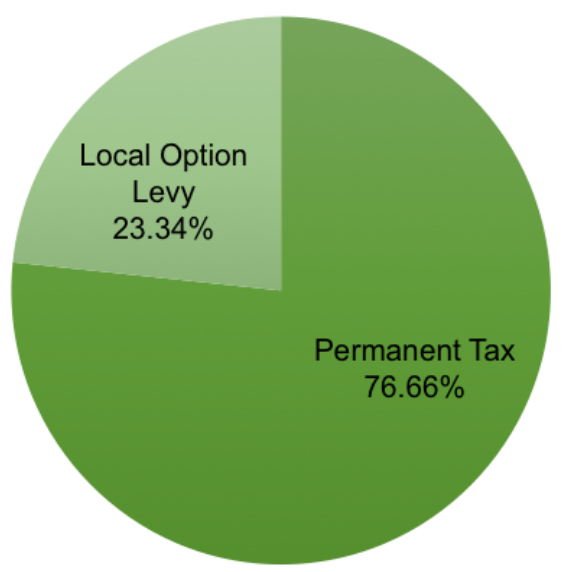




\section{FIGURE 2}

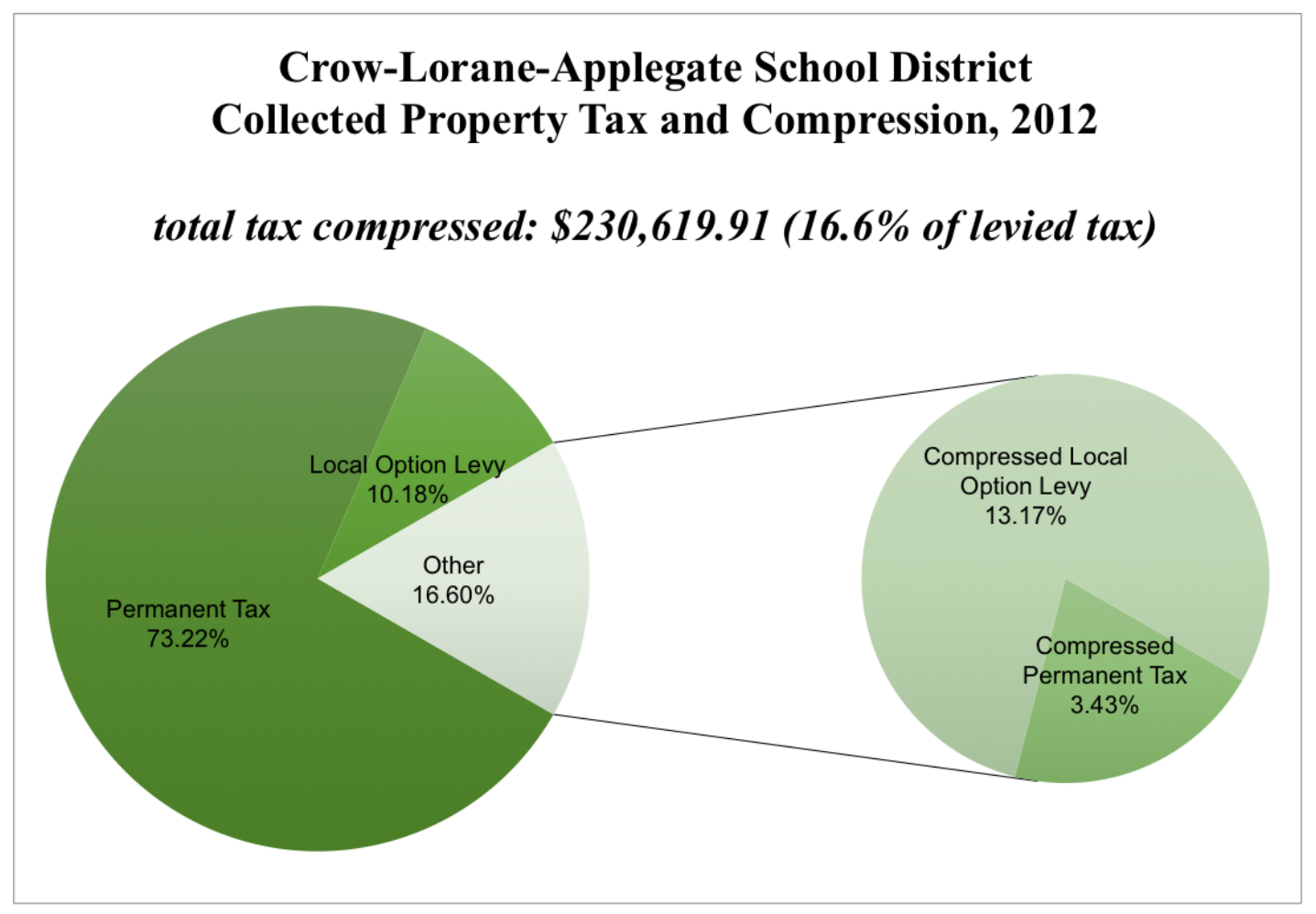

After several tests, we determined that not all collected variables were relevant to our final regression equation. The primary problem we encountered was high correlation between explanatory variables: the three measurements of tax compression (permanent rate, local option levy, and total, which is the combined permanent rate and local option levy) and the four measurements of school district budgets (the operating budget and its summary parts: capital expenditures, instruction, and support services). Because of this correlation, identifying the primary funding link(s) to district rates of meeting or exceeding math standards was less straightforward than we had hoped. In our final regression equation, we dropped all of these variables except for the total tax compression rate.

We also found that our data on student demographics were not as explanatory of MathSuccess as we had anticipated. Variables for the percentages of black, white, and Hispanic students in each district were highly insignificant in multiple regression variations, as were variables for the percentage of students in each district qualifying for the free lunch program or the reduced lunch program; all of the lunch program and individual ethnicity variables were dropped, although MinorityPercentage, the percentage of non-white students in each district, including but not limited to black and Hispanic students, was included in our final regression.

The insignificance of the government-assisted lunch program variables was particularly surprising to us, as we'd hypothesized that low household incomes would negatively impact MathSuccess and hoped to capture that effect with this data as a proxy. Table 1 presents 
summary statistics of our regression's variables, excluding variable manipulations (such as logs and squares) and the binary variables for district and year. (See Table 4 in the appendix for summary statistics of collected variables that were not included in our final regression.) Observations of our explanatory variable-of-interest, TaxCompressionRate, ranged, within one standard deviation of the mean, from o percent to 4.3 percent.

\section{TABLE 1}

\begin{tabular}{|c|c|c|c|c|c|}
\hline \multicolumn{6}{|c|}{ Summary Statistics for Final Variables } \\
\hline Variable & No. Obs. & Mean & Std. Dev. & Min. & Max. \\
\hline MathSuccess & 913 & 65.2 & 13.1 & 14.3 & 95.0 \\
\hline TaxCompressionRate & 888 & 2.0 & 2.3 & 0.0 & 16.8 \\
\hline StudentCount $*$ & 917 & $3,515.0$ & $6,480.9$ & 76.0 & $45,362.0$ \\
\hline MinorityPercentage & 917 & 22.9 & 15.1 & 2.3 & 80.6 \\
\hline Free/RedLunchPct & 908 & 52.2 & 15.1 & 2.5 & 91.7 \\
\hline
\end{tabular}

There are 192 school districts in Oregon, but after dropping 45 districts for which we could not gather consistent data on tax compression, our dependent variable of interest, we landed at a still-sizable collection of data: 147 districts over six academic years, or 882 observations.

Data on the percentage of students in each district enrolled in a English as a Second Language (ESL) program, the talented and gifted (TAG) program, and in a special education program, such as a student individualized education program (IEP), would have been desirable, as we suspect that there are strong correlations between qualification for these programs and performance on state standardized tests. Given the time constraints of this research project, however, it was not possible to obtain this data. Budgets for each program were easily accessible, but they are not reliably reported from district to district or even from year to year, and so they did not yield helpful contributions to our analysis.

We also would have liked to examine the relationship between tax compression and eighth grade student outcomes over a much longer time period-ideally, beginning as early as the 19911992 academic year, at the outset of Oregon's property tax reform. Although this time span may have given us a more complete answer to our research question, it also would have created several problems, the most significant of which would have been accounting for the alterations to state standards for eighth grade mathematics assessment in 2001-2002 and 2006-2007.

\section{RESULTS}

We find that high levels of compression are linked to significantly lower student performance. Our regression results, shown in Table 2, indicate that tax compression does have a significant effect, at the 5 percent level, on the percentage of eighth grade students who meet 
or exceed state standards in mathematics, and that whether the effect is positive or negative depends on the magnitude of the compression rate.

\section{TABLE 2}

\begin{tabular}{|lrrrr|}
\hline \multicolumn{5}{|c|}{ Final Regression Results } \\
\hline \multicolumn{4}{|c}{} & \multicolumn{3}{c|}{ End. variable: MathSuccess } \\
Variable & Robust Coeff. & Std. Error & t & p-value \\
\hline Constant & 32.55 & 50.94 & 0.64 & 0.52 \\
TaxCompressionRate & 1.56 & 0.74 & 2.11 & 0.04 \\
TaxCompressionRate & -0.09 & 0.04 & -2.06 & 0.04 \\
logStudentCount & 7.00 & 6.92 & 1.01 & 0.31 \\
MinorityPercentage & 0.02 & 0.24 & 0.09 & 0.93 \\
MinorityPercentage & 0.01 & 0.00 & 2.21 & 0.03 \\
Free/RedLunchPct & -0.02 & 0.11 & -0.20 & 0.84 \\
Year $*$ & - & - & - & - \\
District $*$ & - & - & - & - \\
\hline
\end{tabular}

The coefficient estimates for our tax compression variable, a positive coefficient (1.56) for the linear term and a negative coefficient (-0.09) for the quadratic, indicate a relationship between tax compression and student outcomes that begins positively and then, at a certain rate of compression, tips into a diminishing trend. To identify that "tipping point" we took the derivative of the equation

(2) $y=\beta_{o}+\beta_{1}$ TaxCompressionRate $+\beta_{2}$ TaxCompressionRate ${ }^{2}+\beta$

(3) $y^{\prime}=\beta_{1}+2 * \beta_{2}$ TaxCompressionRate

and, setting Equation 3 equal to zero and using the coefficient estimates from Table 2 for $\beta_{1}$ and $\beta_{2}$, solved for a TaxCompressionRate "tipping point" of 8.66 percent. 


\section{FIGURE 3}

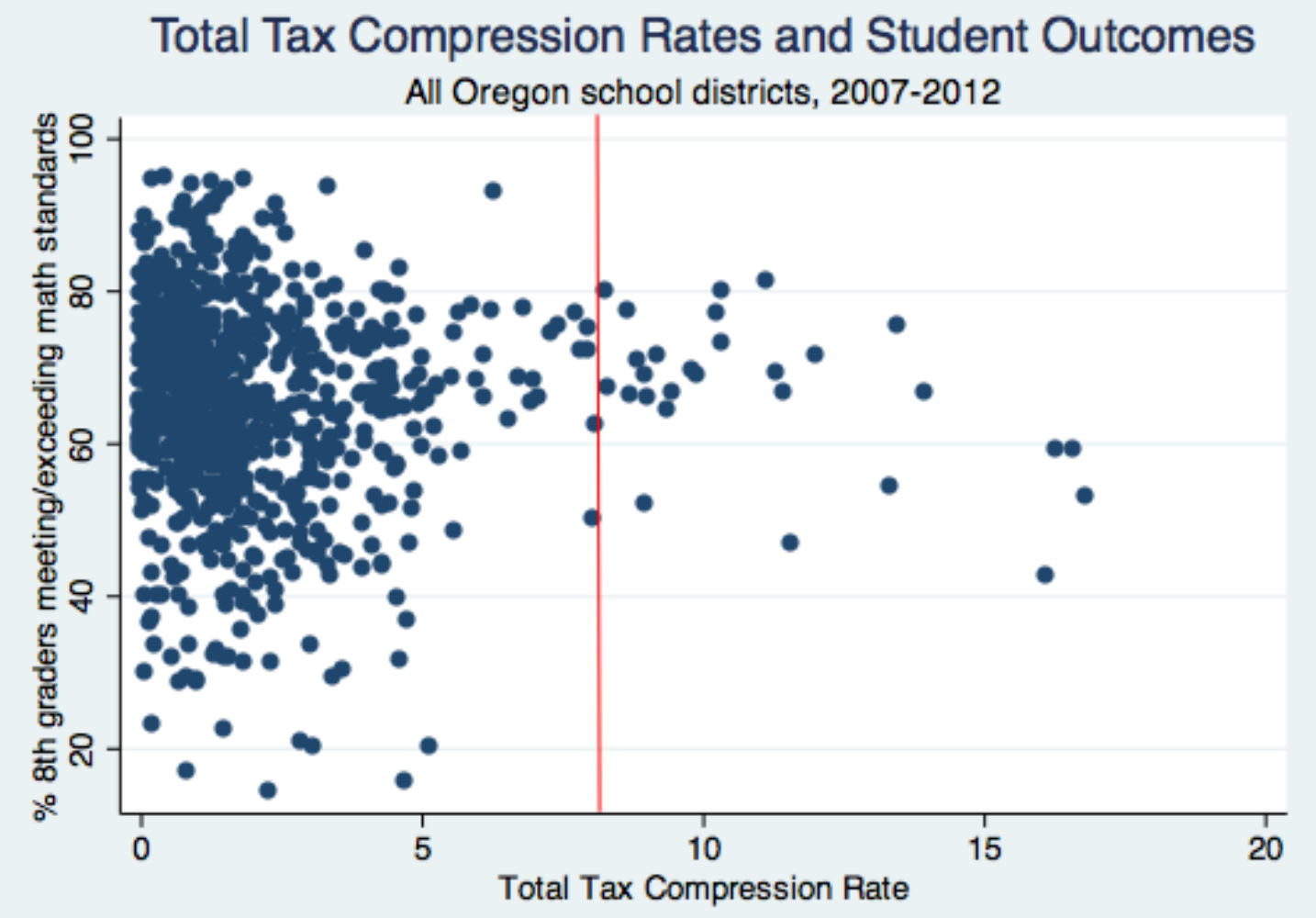

As is roughly illustrated in Figure 3 above and Table 3 below, tax compression significantly and positively affects student outcomes, at a diminishing rate-of-increase, until a school district reaches the 8.66 percent threshold, at which point the positive effects of tax compression on MathSuccess begin to decline as TaxCompressionRate increases. According to our model, the effects of tax compression remain positive until a total compression rate of 17.33 percent is reached. 
TABLE 3

\begin{tabular}{|cc|}
\hline \multicolumn{2}{|c|}{ Effects of TaxCompressionRate } \\
on MathSuccess \\
\hline TaxCompressionRate & MathSuccess ${ }^{*} *$ \\
\hline 0.00 & 0.00 \\
1.00 & 1.47 \\
2.00 & 2.76 \\
3.00 & 3.87 \\
4.00 & 4.80 \\
5.00 & 5.55 \\
6.00 & 6.12 \\
7.00 & 6.51 \\
8.00 & 6.72 \\
9.00 & 6.75 \\
10.00 & 6.60 \\
11.00 & 6.27 \\
12.00 & 5.76 \\
13.00 & 5.07 \\
14.00 & 4.20 \\
15.00 & 3.15 \\
16.00 & 1.92 \\
17.00 & 0.51 \\
18.00 & -1.08 \\
19.00 & -2.85 \\
20.00 & -4.80 \\
${ }^{*}$ calculated based on regression results in Table 2 \\
$*{ }^{*}$ percentage-point deviation from mean attributable to \\
& TaxCompressionRate \\
\end{tabular}

Though no district in Oregon has yet reached a total tax compression rate of 17.33 percent (the highest rate in our data set was 0.5 percentage-points shy, at 16.83 percent, in Morrow School District in 2012), our model predicts that tax compression at this rate or higher will have a significantly negative effect on student outcomes.

We attribute the positive effects of tax compression on student achievement to two possibilities. First, because compression is a consequence of reaching a funding cap, the districts that are experiencing compression are at least attempting to maximize their tax base, and they collected significant revenue given their constraints. Second, there may be a state general fund mechanism that replaces lost property tax revenue to school districts but that overcompensates, doling funds in excess of the compressed revenue.

We believe the eventual negative effects of tax compression may be related to the same state general fund mechanism, which likely maxes out at a certain level of replacement funding, as well as to budget cut constraints faced by school districts due to union contracts with teachers 
and staff. Or, potentially, due to enormous temporary expenses such as construction costs, which, if our sense is correct and tax compression is largely unanticipated by local administrators, may have been committed to after a local option levy was approved but before collected tax revenues fell short of projections.

\subsection{THE DIFFERENCES IN DISTRICTS OVER THE “TIPPING POINT”}

Twenty-six observations in our dataset reached the 8.66 percent "tipping point" for total tax compression rate; half of those observations included local option levies. ${ }^{3}$ Downes and Figlio (1998) find a stronger negative relationship between tax limits and student outcomes in poorer school districts, specifically those districts with lower per-pupil expenditures in the base year of their analysis, so in closer examination of the differences between districts with high rates of compression and those low or no compression, we turned our attention primarily to district funding levels. When comparing the per-pupil operating budgets for the two district groups in Figure 4, we find that "tipped" districts seem to be fairly representative of the center distribution of all districts (i.e., the means and standard deviations are comparable across the two groups). Neither the richest nor the poorest districts are included in the "tipped" group.

\section{FIGURE 4}

\section{"Tipped" districts—what's different?}

All districts

Mean year: 2009.5 (right in middle of sample)

Operating costs per student

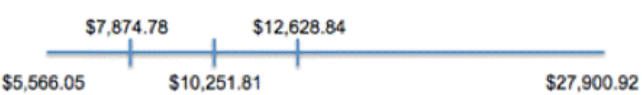

Capital expenditu res per student:

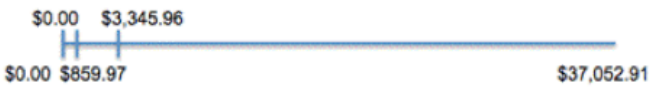

Compression $>8.66 \%$

Mean year: 2010 (skews towards later years)

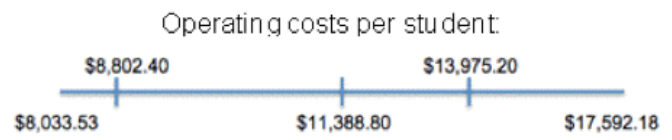

Capital expen ditu res per stu dent:

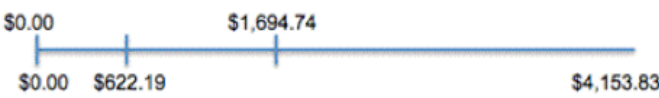

${ }^{3}$ See Table 5 in the appendix for summary statistics of "tipped" districts. 
Looking at per-pupil capital expenditures across the two district groups, we see that "tipped" districts are spending less: the mean and standard deviation for "tipped" districts are $\$ 622.19$ and $\$ 1,072.55$, respectively, while the mean and standard deviation for all districts are $\$ 859.97$ and $\$ 2,485.99$, respectively. Nearly 15 percent of all districts are spending more on capital expenditures than the maximum amount spent by a "tipped" district; half of all districts are spending more than the average "tipped" district. This data seems to support the findings of McMillen and Singell (2007), in that the compression-imposed revenue constraints of Oregon's "tipped" districts appear to be channeled towards non-instructional budget cuts.

\section{CONCLUSION}

This study attempts to measure the effects of property tax compression, tax revenue expected but not collected due to tax caps, on Oregon's education production by regressing the rate of compressed tax (as a percentage of total tax levied) and school district demographic data against the percentage of eighth grade students who meet or exceed state standards on the mathematics assessment. The primary aim of this research is to determine whether tax compression has an effect on school outcomes that is distinct from the effects of the existence of a tax cap, or a reduction in overall funding levels.

The principal finding of our research is that property tax compression does have an effect on student achievement, significant at the 5 percent level. Tax compression positively affects student outcomes, at a diminishing rate-of-growth, until a school district reaches a tax compression rate threshold of 8.66 percent, after which point the positive effects of tax compression on student achievement begin to decline as the tax compression rate continues to increase. According to our model, the effects of tax compression remain positive until a total compression rate of 17.33 percent is reached; we predict that compression rates above 17.33 percent will negatively affect student achievement.

While the results of our study establish a significant relationship between property tax compression rates and school outcomes, further examination of the state funding mechanisms that tax compression triggers would illuminate the counter-intuitive result that low rates of compression have positive effects on student achievement. We have suggested two possible explanations for these results: 1) that districts levying any local option are at least attempting to maximize their tax base, and therefore constitute a self-selected group of proactively managed districts, and 2) that there exists a state funding mechanism that replaces or attempts to replace lost tax compression revenue to school districts, but that does so imprecisely, effectively overcompensating the district. Further research on this subject should closely examine the equations used by the state for any general fund adjustments made after a district's experienced tax compression. Furthermore, a more complete picture of the constraints school districts face in making budget cuts, when presented with lower-than-expected property tax revenue, may also contribute to our understanding of tax limitations and education; our results suggest that school districts in this position are making cuts to capital expenditures, which seems consistent with previous findings (McMillen and Singell, 2007), but more research is needed. 


\section{APPENDIX}

\section{FIGURE 8}

\section{An illustration: 4239 NE 7th Ave.}

4 beds, 3 baths, 2,280 sq. $\mathrm{ft}$. Desirable corner lot in PDX Asking price: $\$ 499,900$ Sale price, April 1: $\$ 490,000$

Assessed Value (2013): \$14,030 Real Market Value: $\$ 114,000$

Property tax: $\$ 339$ Effective rate: $0.069 \%$

Data and image source: Trulia.com

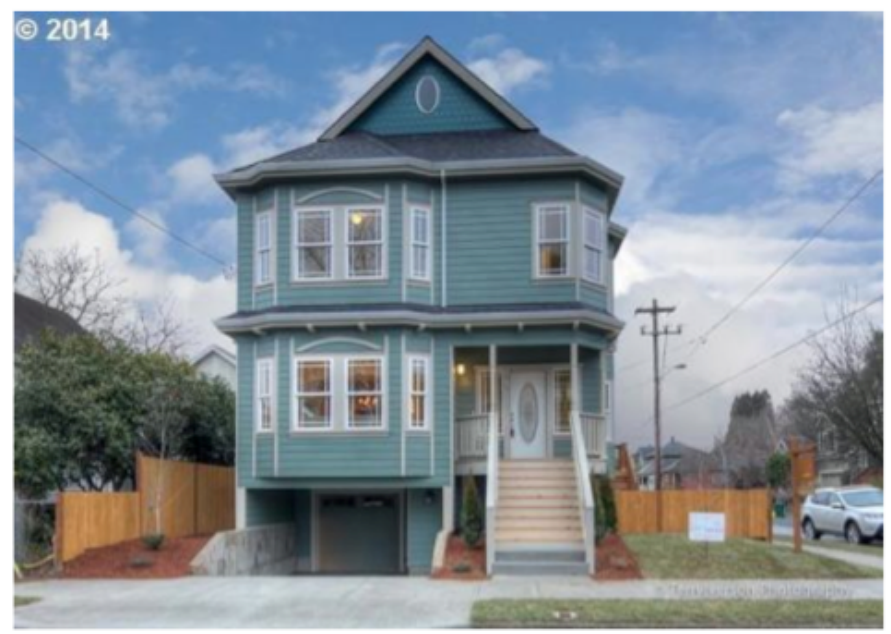

(thtto://www trullia.com/homes/Oregon/Portland/sold/11000392644-4239-NE-7th-Ave-Portland-OR-97211) 


\section{FIGURE 9}

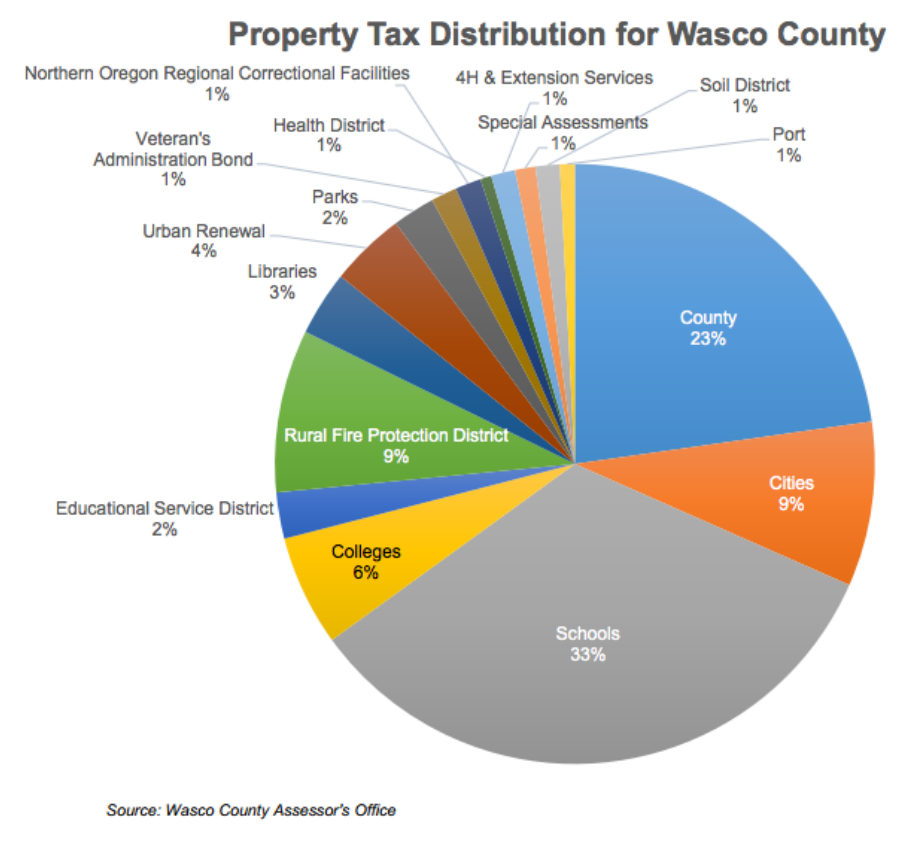




\section{FIGURE 10}

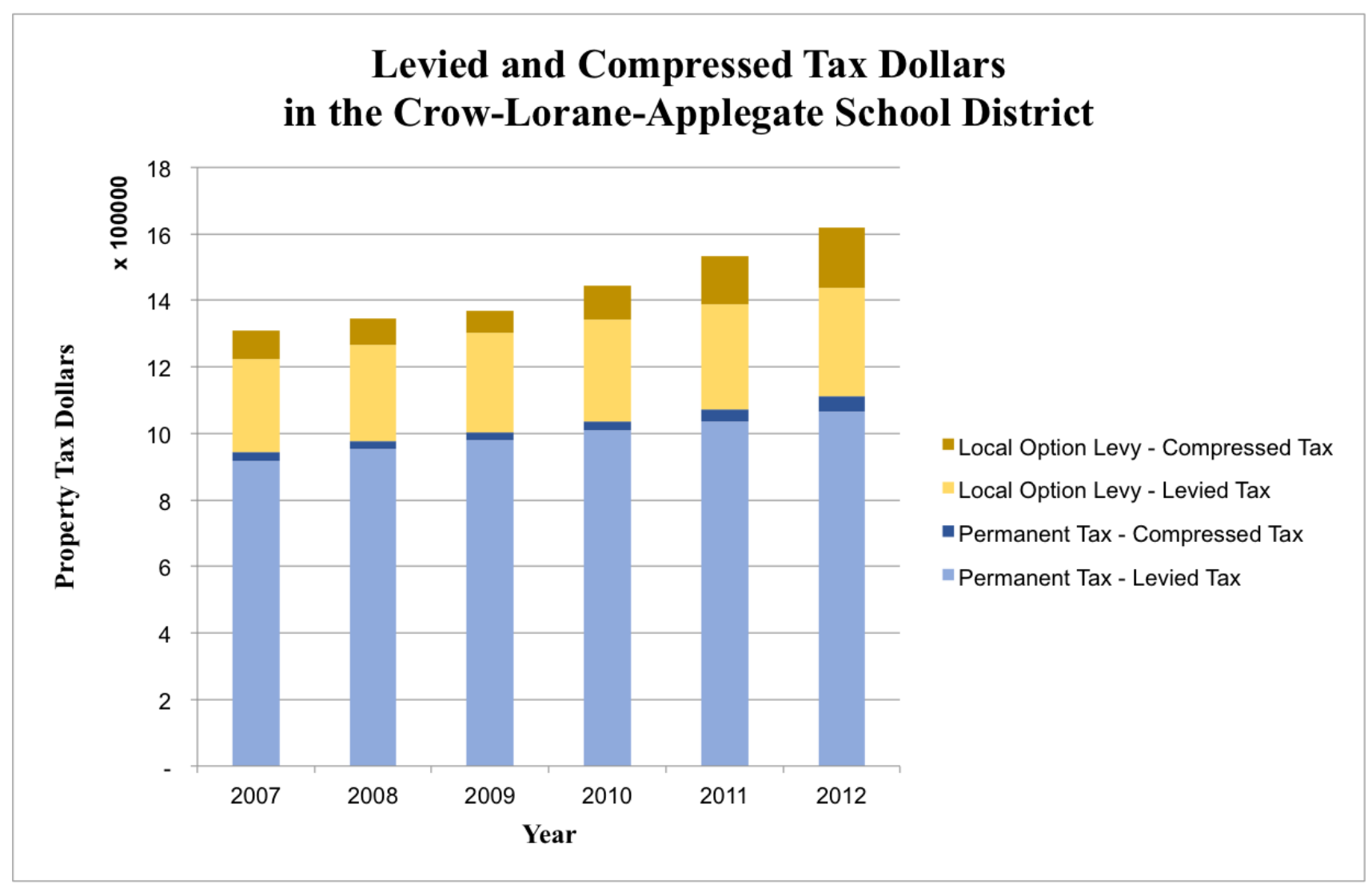


TABLE 4

\begin{tabular}{|c|c|c|c|c|c|}
\hline \multicolumn{6}{|c|}{ Summary Statistics for Collected Variables } \\
\hline Variable & \# Obs. & Mean & Std. Dev. & Min. & Max. \\
\hline MathSuccess & 913 & 65.2 & 13.1 & 14.3 & 95.0 \\
\hline TaxCompressionRate & 888 & 2.0 & 2.3 & 0.0 & 16.8 \\
\hline StudentCount $*$ & 917 & $3,515.0$ & $6,480.9$ & 76.0 & $45,362.0$ \\
\hline MinorityPercentage & 917 & 22.9 & 15.1 & 2.3 & 80.6 \\
\hline Free/RedLunchPct & 908 & 52.2 & 15.1 & 2.5 & 91.7 \\
\hline BlackPercentage ** & 917 & 1.1 & 1.7 & 0.0 & 15.4 \\
\hline HispanicPercentage ** & 917 & 14.6 & 14.4 & 0.0 & 78.0 \\
\hline WhitePercentage ** & 917 & 76.2 & 14.9 & 19.4 & 97.1 \\
\hline OperatingBudget $* *$ & 917 & $3.3 \mathrm{e}+7$ & $6.3 e+7$ & $1,504,991$ & $5.3 \mathrm{e}+8$ \\
\hline OperatingPer:Student $* *$ & 917 & $10,251.8$ & $2,377.0$ & $5,566.1$ & $27,900.9$ \\
\hline CapitalExpenditures $* *$ & 727 & $4,160,645$ & $1.2 \mathrm{e}+07$ & 6.2 & $1.2 \mathrm{e}+08$ \\
\hline CapitalPerStudent $* *$ & 727 & $1,084.7$ & $2,748.3$ & 0.0 & $37,052.9$ \\
\hline InstructionBudget $* *$ & 765 & $1.7 \mathrm{e}+07$ & $3.3 e+07$ & $618,192.1$ & $2.5 \mathrm{e}+08$ \\
\hline SupportServBudget $* *$ & 765 & $1.1 \mathrm{e}+07$ & $2.1 \mathrm{e}+07$ & $579,252.3$ & $1.8 \mathrm{e}+08$ \\
\hline LocalOpCompRate ** & 86 & 15.8 & 15.1 & 1.1 & 69.9 \\
\hline PermTaxCompRate ** & 873 & 1.8 & 1.9 & 0.0 & 13.9 \\
\hline
\end{tabular}

TABLE 5

\begin{tabular}{|c|c|c|c|c|c|}
\hline \multicolumn{6}{|c|}{ Summary Statistics for "Tipped" Districts } \\
\hline Variable & \# Obs. & Mean & Std. Dev. & Min. & Max. \\
\hline MathSuccess & 26 & 66.1 & 9.9 & 42.5 & 81.3 \\
\hline TaxCompressionRate & 26 & 11.4 & 2.7 & 8.68 & 16.83 \\
\hline StudentCount $*$ & 26 & $4,572.3$ & $9,208.3$ & 160 & $45,362.0$ \\
\hline MinorityPercentage & 26 & 29.0 & 19.0 & 2.5 & 66.7 \\
\hline Free/RedLunchPct & 26 & 51.7 & 16.4 & 21.8 & 79.4 \\
\hline BlackPercentage ** & 26 & 1.0 & 2.1 & 0.0 & 11.1 \\
\hline HispanicPercentage $* *$ & 26 & 20.9 & 20.9 & 0.0 & 64.7 \\
\hline WhitePercentage ** & 26 & 70.6 & 18.6 & 33.0 & 95.0 \\
\hline OperatingBudget $* *$ & 26 & $4.6 e+7$ & $1.1 \mathrm{e}+8$ & $1,815,210$ & $5.1 \mathrm{e}+8$ \\
\hline OperatingPerStudent $* *$ & 26 & $11,388.8$ & $2,586.4$ & $8,033.5$ & $17,592.2$ \\
\hline CapitalExpenditures $* *$ & 23 & $5,570,600$ & $1.1 \mathrm{e}+07$ & $3,677.9$ & $3.5 \mathrm{e}+07$ \\
\hline CapitalPerStudent $* *$ & 23 & 703.3 & $1,116.9$ & 6.73 & $4,153.8$ \\
\hline InstructionBudget $* *$ & 18 & $1.0 \mathrm{e}+07$ & $1.3 \mathrm{e}+07$ & $968,233.4$ & $4.1 \mathrm{e}+07$ \\
\hline SupportServBudget $* *$ & 18 & $6,255,310$ & $7,364,156$ & $615,755.4$ & $2.4 \mathrm{e}+07$ \\
\hline LocalOpCompRate ** & 13 & 40.8 & 19.1 & 18.4 & 69.9 \\
\hline PermTaxCompRate ** & 26 & 6.5 & 4.4 & 0.8 & 13.9 \\
\hline
\end{tabular}


TABLE 6

\begin{tabular}{|c|c|c|c|c|}
\hline & ondary Reg1 & $\frac{\text { sion Resul }}{\text { End. variable }}$ & $\begin{array}{l}\text { perat } \\
\text { square }\end{array}$ & $\begin{array}{l}\text { igBudget } \\
\text { 1: } 0.9984\end{array}$ \\
\hline Variable & Robust Coeff. & Std. Error & $\mathrm{t}$ & p-value \\
\hline TaxCompressionRate & -0.0033 & 0.0044 & -0.74 & 0.46 \\
\hline TaxCompressionRate ${ }^{2}$ & 0.0001 & 0.0003 & 0.46 & 0.65 \\
\hline logStudentCount & 0.7064 & 0.0763 & 9.26 & 0.00 \\
\hline MinorityPercentage & -0.0030 & 0.0017 & -1.74 & 0.08 \\
\hline MinorityPercentage ${ }^{2}$ & 0.0000 & 0.0000 & 0.34 & 0.74 \\
\hline Free/RedLunchPct & 0.0002 & 0.0010 & 0.16 & 0.87 \\
\hline Year * & - & - & - & - \\
\hline District * & - & - & - & - \\
\hline
\end{tabular}

TABLE 7

\begin{tabular}{|c|c|c|c|c|}
\hline \multicolumn{5}{|c|}{ Secondary Regression Results, "Tipped" Districts } \\
\hline \multicolumn{5}{|c|}{$\begin{array}{r}\text { End. variable: logOperatingBudget } \\
\text { R-squared: } 0.9984\end{array}$} \\
\hline Variable & Robust Coeff. & Std. Error & $\mathrm{t}$ & p-value \\
\hline TaxCompressionRate & 0.0233 & 0.0480 & 0.49 & 0.65 \\
\hline TaxCompressionRate ${ }^{2}$ & -0.0009 & 0.0019 & -0.47 & 0.66 \\
\hline logStudentCount & 0.5227 & 0.5878 & 0.89 & 0.42 \\
\hline MinorityPercentage & 0.0019 & 0.0139 & 0.14 & 0.89 \\
\hline MinorityPercentage ${ }^{2}$ & 0.0000 & 0.0002 & 0.32 & 0.76 \\
\hline Free/RedLunchPct & -0.0005 & 0.0092 & -0.06 & 0.96 \\
\hline Year * & - & - & - & - \\
\hline District * & - & - & - & - \\
\hline
\end{tabular}




\section{ACKNOWLEDGEMENTS}

For helpful comments, unwaning interest, and seemingly undivided attention, we are grateful to our advisor, Professor Joe Stone.

\section{REFERENCES}

A Brief History of Oregon Property Taxation. Salem: Oregon Dept. of Revenue, 2009. PDF File.

City Property Tax Data. Salem: League of Oregon Cities, 2013. PDF File.

Coate and VanderHoff. 1999. Public School Spending and Student Achievement: The Case of New Jersey. Cato Journal, 19:1, 85-99.

Downes and Figlio. 1998. School finance reforms, tax limits, and student performance: Do reforms level-up or dumb down? Memo, Tufts University, Cambridge, MA.

Dye, et. al. 2005. Are Property Tax Limitations More Binding Over Time? National Tax Journal, Vol. LVIII, No. 2, 215-225.

Eberts, Stone and Hollenbeck. 2004. Teachers' Unions, Outcomes and Reform Initiatives. Teachers' Unions and Education Policy. Henderson, et. al. eds. Elsevier Press

Eberts and Stone. 2002. Teacher Performance Incentives and Student Outcomes. Journal of Human Resources, 37:4. 913-27.

Hanushek and Raymond. 2005. Does School Accountability Lead to Improved Student Performance? Journal of Policy Analysis and Management, Vol. 24, No. 2, 297-327.

Hanushek and Raymond. 2004. The Effect of School Accountability Systems on the Level and Distribution of Student Achievement. Journal of the European Economic Association, 2(23): $406-415$.

Hodge, et. al. 2013. Tax Base Erosion and Inequity From Michigan's Assessment Growth Limit: The Case of Detroit. CESifo WP no. 4098.

Hoxby, 2004. Productivity in Education: The Quintessential Upstream Industry. SouthernEconomic Journal, 71(2), 209-231.

Hoxby. 2001. All School Finance Equalizations Are Not Created Equal. Q. J. E. 116:4, 1189 1231.

Hoxby. 1998. How Much Does School Spending Depend on Family Income? The Historical Origins of the Current School Finance Dilemma. American Economic Review. Vol. 88, No. 2, 309-314.

Linhares. 2011. Recent History of Oregon's Property Tax System: With an Emphasis on Its Impact on Multnomah County Local Governments. Ed. Provost. Portland: Multnomah County Tax Supervising and Conservation Committee. PDF File. 
McMillen and Singell. "School Finance Reforms and Property Tax Limitation Measures." School Finance Reforms and Property Tax Limitation Measures: Fiscal Decentralization and Land Policies. Ed. Ingram and Hong. 2007, Cambridge, Massachusetts. Cambridge:Lincoln Institute of Land Policy, n.d. Print.

Neal and Schazenbach. 2007. Left Behind by Design: Proficiency Counts and Test-Based Accounting. NBER WP no. 13681.

Oregon Property Tax Statistics, Fiscal Year 2012-2013. Salem: Oregon Dept. of Revenue, 2013. PDF File.

"Public Education in Oregon." Oregon Blue Book. Oregon Secretary of State, n.d. Web. 9 March 2014.

SPECIAL REPORT: Voter-Approved Tax Levies Losing More Money Than Ever Before. Salem: League of Oregon Cities, 2013. PDF File.

Where The Money Goes: A Report on City Property Taxes. Salem: League of Oregon Cities, 2013. PDF File. 